\title{
Mycological investigations in beef and chicken luncheon
}

\author{
Fatma H. M. Ali', Refaat M. Farghaly ${ }^{2}$, Hammad A. M. ${ }^{3}$ \\ ${ }^{1}$ Department of Food Hygiene and Control, Faculty of Veterinary Medicine, \\ Beni-Suef University, Beni-Suef, Egypt \\ ${ }^{2}$ Department Food Hygiene and Control, Faculty of Veterinary Medicine \\ South Valley University, Qena, Egypt. \\ ${ }^{3}$ Animal Health Research Institute, Dokki, Giza, Egypt.
}

\begin{abstract}
A total of 40 samples of beef and chicken luncheon (20 samples for each) were collected from different markets in Giza city. Samples were subjected to Mycological investigations. Beef luncheon were highly contaminated than chicken luncheon $(3.1 \mathrm{x}$ $\left.10^{3} / g \pm 0.3 \times 10^{3}\right)$ and $\left(4.0 \times 10^{2} / g \pm 0.2 \times 10^{2}\right)$ respectively. Seven mould genera were isolated from examined samples. The majority of which were Aspergillus $(19.7 \%$ and 18.1\%) and Penicillium (18.9\% and $15.7 \%)$, while, Mucor (7.1\% and $4.7 \%)$, Cladosporium (4.7\% and $3.9 \%)$ and other genera were also isolated from the same samples but in low percentages from beef and chicken luncheon respectively. The predominant identified Aspergillus species were; $A$. niger $(18.7 \%$ and $14.5 \%), A$. flavus $(18.7 \%$ and $12.5 \%)$ and $A$. ochraceous $(6.3 \%$ and $6.3 \%)$ in the two products respectively. The main identified Penicillium species were; $P$. citrinium $(20.6 \%$ and $13.6 \%), P$. expansum $(11.4 \%$ and $13.6 \%)$ and $P$. verrucosum $(6.8 \%$ and $6.8 \%)$ from the same products respectively. Examination for mycotoxin production revealed the detection of ochratoxin $A$ at a higher level (mean 21.0 and $27.0 \mathrm{ng} / \mathrm{kg}$ ) from $2(10 \%)$ samples of beef luncheon and one (5\%) sample of chicken luncheon, respectively. Aflatoxin B1 (mean 15.3 and $9.8 \mathrm{ng} / \mathrm{kg}$ ) was detected in $4(20 \%)$ samples of beef luncheon and $3(15 \%)$ samples of chicken luncheon, respectively. Other mycotoxins (AFB2, AFG1, AFG2 and T-2) were detected but in minor levels. Public health significance of the identified mould species and the detected mycotoxins were discussed.
\end{abstract}

Our diet is supplemented with different food items; as luncheon that is available under a variety of conditions (frozen, canned or dehydrated). It may be filled pre- cooked and become ready for heating and serving. With unhygienic preparation, moulds may attack luncheon and render it unfit for consumption due to spoilage or deterioration. The level of such contamination depends upon the used ingredients and the processing methods. (Giuseppe, et al., 2004) isolated five genera from meat products of three different producers, in which Eurotium spp., Aspergillus spp. and Penicillium spp. were the main strains. The main sources of contamination are the air and the stored rooms, rather than the raw meat. The growth of different strains depended on the temperature and the relative humidity in the stored chambers. The most frequently encountered fungi from luncheon meat were Aspergillus niger, A. flavus, Penicillium chrysogenum, Rhizopus stolonifer, Mucor circinelloides. Less common were Cladosporium sphaerospermum, Alternaria alternata, Mycosphaerella tassiana, Penicillium aurantiogriseum and Penicillium oxalicum (Ismail, et al., 1999).

Mycotoxins are extremely harmful, sometimes lethal to animals and human beings. The toxic potential of several toxin-producing moulds or a limited number of mycotoxins may occurred due to contamination of human food supply whether by direct consumption of these agents or via domestic animals used for meat production (Fishbein, 1972; Bocarov-Stancic, et al., 1995 and Khan, et al., 1998). Many of these toxins are potent neurotoxins, carcinogens and may cause degenerative changes in liver, spleen and kidney (Atlas-Ronald, 1995).

Aflatoxicosis is food poisoning that results from ingestion of aflatoxins in contaminated food. The aflatoxins are group of structurally related toxic compounds produced by certain strains of the fungi Aspergillus flavus and A. parasiticus. Under favourable conditions of temperature and humidity, these fungi grow on certain foods, resulting in the production of aflatoxins. The species were the predominant aflatoxinproducing moulds isolated from processed meat products including luncheon. The major 
aflatoxins of concern are designated B1, B2, G1, and G2. These toxins are usually found together in various foods in various proportions. However, aflatoxin B1 is usually predominant and is the most toxic (Aziz and Youssef, 1991 and FDA, 1992). Ochratoxin A (OA) was firstly isolated from the culture of Aspergillus ochraceus and now is produced by a large number of Aspergillus and Penicillium species. This mycotoxin represents one of closely related derivatives of isocuumarine, which mainly reported in temperate areas. It was found as a contaminant in the large number of commodities and animal organs such as kidney and liver. Toxicological studies indicated that $\mathrm{OA}$ is a teratogenic, mutagenic and carcinogenic mycotoxin with the strong toxic effects on liver and kidney (George and Lechtman, 1973 and Shengand Jiu, 2003).

Trichothecenes are produced by species of Fusarium, Trichoderma and Stachybotrys. Out of 30 known trichothecens; T- 2 toxin is of common occurrence, and cause hyperestrogenic syndrome, hemorrhage and abortion. If it is ingested in sufficient quantity, T-2 toxin can severely damage the entire digestive tract and cause rapid death due to internal hemorrhage. T-2 has been implicated in human diseases alimentary toxic aleukia and pulmonary hemosiderosis (Haschek and Colin, 1991).

Therefore, this study was planned to evaluate the mould contamination and mycotoxin residues in local beef and chicken luncheon. Furthermore, the isolated species of Aspergillus and Penicillium that recovered from examined samples were subjected to further identification.

\section{Materials and Methods}

The following conventional standardizing methods were carried out according to (Samson and Hoekstra, 1996).

Sampling. A total of 40 samples of beef and chicken luncheon were collected from different markets in Giza city (20 for each). The samples were transported in an insulated ice bag to the laboratory without delay .Ten grams of each sample were homogenized with $90 \mathrm{ml}$ sterile peptone water $(0.1 \%)$ in sterile jar using a homogenizer (Universal laboratory Aid made in Poland). Ten-fold dilutions up to $10^{6}$ using sterile peptone water $(0.1 \%)$ were prepared. Malt extract (Oxoid, CM 59 and PH $5.4 \pm 0.2$ ) and Czapeck's-Dox agar (Oxoid, CM97 and pH 6.8 +0.2 ) used for plating. The plates were incubated at $25^{\circ} \mathrm{C}$ for 7 days and daily examined for detection of mould growth.
Isolation and identification. Detected colonies in Petri dishes were inoculated with sterile mycological needles into sterile slope agar (2\% malt extract agar; Oxoid,CM59 pH: 6.8) and incubated at $25^{\circ} \mathrm{C}$ for 5 days. The summation of inoculated malt extract slopes multiplied by the corresponding dilutions expresses the total mould count per gram $(\mathrm{TMC} / \mathrm{g})$ of the sample. Identification of mould species was carried out on pure cultures based on 3-point method and slide-culture technique. These methods of differentiation between mould species mainly depended on their taxonomic information and morphology of the colony, as well as, pigmentation of the reverse surface and fungus structure, according to (Egmond, et al., 1996 and Samson and Hoekstra, 1996).

Detection of mycotoxins. Twenty five grams of each sample were homogenized with $100 \mathrm{ml}$ of chloroform for $5 \mathrm{~min}$ by a homogenizer (universal laboratory aid made in Poland). Extraction was repeated three times. The combined chloroform extract was washed by distilled water, dried over anhydrous sodium sulphate, filtered and concentrated to near dryness on a rotator- evaporator. The residue was diluted with chloroform to one $\mathrm{ml}$. The chloroform solution was analyzed for the presence of aflatoxins, ochratoxin A and T- 2 toxin by using thin- layer chromatographic procedures (Gimeno, 1979).

The aflatoxin level was analyzed and confirmed using trifluoroacetic acid derivative formation (A.O.A.C., 1984). Ochratoxin A was quantitively determined according to (Scott, et al., 1972 and Nesheim et al., 1973). T- toxin was quantitively determined by the method of (Schroeder and Kalton, 1975).

\section{Results and Discussion}

Out of 20 samples of meat luncheon, 9 (45\%) were contaminated with moulds with mean value of TMC $3.1 \times 10^{3} \pm 0.3 \times 10^{3}$ per one gram (CFU $/ \mathrm{g})$. The incidence of mould contamination in chicken luncheon was $4(20 \%)$ with mean value of $4.0 \times 10^{2} \pm 4.0 \times 10^{2} / \mathrm{g}$, (Table 1). The obtained results declared that the beef luncheon were highly contaminated with moulds than chicken luncheon, and this could be attributed to the entry of moulds into the gastrointestinal tract of food animals in association with ingested feed. This agrees with that reported by (Hess, et al., 1995 and Khan, et al., 1998).

Results shown in Table (2) revealed that 127 mould strains belong to 7 genera were isolated from the examined samples of beef and chicken 
Table (1): Total mould count of the examined luncheon samples.

\begin{tabular}{cccccccc}
\hline & \multicolumn{3}{c}{+ +ve sample } & \multicolumn{4}{c}{ Total mould count $/ 1$ g } \\
\cline { 2 - 7 } Samples* & No. & $\%$ & Min. & Max. & Mean. & SE \\
\hline Meat luncheon & 9 & 45 & $1 \times 10^{2}$ & $6 \times 10^{3}$ & $3.1 \times 10^{3}$ & $0.3 \times 10^{3}$ \\
Chicken luncheon & 4 & 20 & $3 \times 10$ & $8 \times 10^{2}$ & $4 \times 10^{2}$ & $0.2 \times 10^{2}$ \\
\hline
\end{tabular}

*No. of examined samples is 20 for each.

Table (2): Isolated mould genera in examined luncheon samples.

\begin{tabular}{lcccccc}
\hline \multicolumn{1}{c}{ Samples } & \multicolumn{2}{c}{ Beef luncheon } & \multicolumn{2}{c}{ Chicken luncheon } & \multicolumn{2}{c}{ Total } \\
\hline \multicolumn{1}{c}{ Mould genera } & No. & *F\% & No. & F\% & No. & F\% \\
\hline Acromonium & 1 & 0.8 & 0 & 0.0 & 1 & 0.8 \\
Alternaria & 2 & 1.6 & 2 & 1.6 & 4 & 3.2 \\
Aspergillus & 25 & 19.7 & 23 & 18.1 & 48 & 37.8 \\
Cladosporium & 6 & 4.7 & 5 & 3.9 & 11 & 8.6 \\
Fusarium & 2 & 1.6 & 2 & 1.6 & 4 & 3.2 \\
Mucor & 9 & 7.1 & 6 & 4.7 & 15 & 11.8 \\
Penicillium & 24 & 18.9 & 20 & 15.7 & 44 & 34.6 \\
Total & 69 & 54.3 & 58 & 45.7 & 127 & 100 \\
\hline
\end{tabular}

*Frequency\%

Table (3): Aspergillus species in examined luncheon samples.

\begin{tabular}{lcccccc}
\hline \multicolumn{1}{c}{ Samples } & \multicolumn{2}{c}{ Beef luncheon } & \multicolumn{2}{c}{ Chicken luncheon } & \multicolumn{2}{c}{ Total } \\
\hline Aspergillus spp. & No. & $*$ F\% & No. & F\% & No. & F\% \\
\hline A. candidus & 1 & 2.1 & 2 & 4.2 & 3 & 6.3 \\
A. flavus & 9 & 18.7 & 6 & 12.5 & 15 & 31.2 \\
A. fumigatus & 1 & 2.1 & 2 & 4.2 & 3 & 6.3 \\
A. nidulans & 0 & 0.0 & 1 & 2.1 & 1 & 2.1 \\
A. niger & 9 & 18.7 & 7 & 14.5 & 16 & 33.3 \\
A. ochraceous & 3 & 6.3 & 3 & 6.3 & 6 & 12.5 \\
A. terreus & 2 & 4.2 & 2 & 4.2 & 4 & 8.3 \\
Total & 25 & 52.1 & 23 & 47.9 & 48 & 100 \\
\hline
\end{tabular}

* Frequency $\%$

Table (4) : Penicillium species in examined luncheon samples.

\begin{tabular}{lcccccc}
\hline \multicolumn{1}{c}{ Samples } & \multicolumn{2}{c}{ Beef luncheon } & \multicolumn{2}{c}{ Chicken luncheon } & \multicolumn{2}{c}{ Total } \\
\hline Penicillium spp. & No. & $*$ F\% & No. & F\% & No. & F\% \\
\hline $\boldsymbol{P}$. citrinium & 9 & 20.6 & 6 & 13.6 & 15 & 34.1 \\
$\boldsymbol{P}$. claviformi & 1 & 2.3 & 1 & 2.3 & 2 & 4.5 \\
$\boldsymbol{P}$. corymbiferum & 2 & 4.5 & 2 & 4.5 & 4 & 9.1 \\
$\boldsymbol{P}$. digitorium & 0 & 0.0 & 1 & 2.3 & 1 & 2.3 \\
$\boldsymbol{P}$. expansum & 5 & 11.4 & 6 & 13.6 & 11 & 25.0 \\
$\boldsymbol{P}$. rubrum & 4 & 9.0 & 1 & 2.3 & 5 & 11.4 \\
$\boldsymbol{P}$. verrucosum & 3 & 6.8 & 3 & 6.8 & 6 & 13.6 \\
Total & 24 & 54.6 & 20 & 45.4 & 44 & 100 \\
\hline
\end{tabular}

*Frequency $\%$ 
luncheon. The most commonly isolated moulds belong to the genera of Aspergillus (19.7\% and $18.1 \%$ ) and Penicillium (18.9\% and $15.7 \%$ ), respectively. Mucor spp. were detected with incidences $(7.1 \%$ and $4.7 \%)$, from beef and chicken luncheon samples, respectively; They are widely distributed in soil, food, poultry feed and animal tissues. It usually appears as a white colony on media that becomes brownish-gray with age (Hanlin, 1973).

Cladosporium spp. are the main cause of black spot affecting chilled meat in cold stores at temperature around $0^{\circ} \mathrm{C}$. These species were recovered at rates of $(4.7 \%$ and $3.9 \%)$ for beef and chicken luncheon samples, respectively, (Table 2). Alternaria and Fusarium spp. were identified but at lower rate $(1.6 \%)$ from both types of the examined luncheon samples. Alternaria spp. are common saprophytic fungi which can grow at a minimal $\mathrm{a}_{\mathrm{w}}(0.85)$ and a wide range of temperature $\left(-5\right.$ to $\left.36^{\circ} \mathrm{C}\right)$, thereby it could be isolated from many kinds of foodstuffs, soil and air (Ellis, 1971 and Domsch, et al., 1993). Fusarium colonies usually growing fast, pale or bright-colored in yellow, brownish, pink reddish, violet or lilac shades. These strains are highly toxic for human and animals because of their ability in production of several types of mycotoxins as fuminisins and trichothecenes (Haschek, et al., 1991). Interestingly Acromonium species were isolated only from the examined samples of beef luncheon; constituting $0.8 \%$ of the isolated strains.

The obtained results presented in Table (3) revealed that 48 Aspergillus species were isolated from beef and chicken luncheon samples and could be identified as A. niger (18.7\% and $14.5 \%)$, A. flavus $(18.7 \%$ and $12.5 \%$ ) and $A$. ochraceous (6.3\% and 6.3\%), respectively. Furthermore, $A$. terreus, $A$. candidus, A. fumigatus and A. nidulans could be also isolated, but at low percentages. These values are similar to that recorded by (Farghaly, 1993 and Mahmoud, et al., 2001).

Results in (Table 4) illustrated that 44 Penicillium species were isolated and identified as, $P$. citrinium $(20.6 \%$ and $13.6 \%), P$. expansum $(11.4 \%$ and $13.6 \%)$ and $P$. verrucosum $(6.8 \%$ and $6.8 \%)$ from the examined samples of beef and chicken luncheon, respectively. Moreover, $P$. rubrum, $P$. corymbiferum, $P$. claviformi and $P$. digitorium were detected but at low values. The findings are in agreement with that reported by (Zaki, et al., 1995 and Ahmed, 1997).

Results given in Table (5) revealed that ochratoxin A had the highest contents (mean 21.0 and $27.0 \mathrm{ng} / \mathrm{kg}$ ), which recovered from 2 $(10 \%)$ samples of beef luncheons and one sample of chicken luncheon (5\%), respectively. These values are higher than the maximum permissible limit (Sizoo and Egmond 2005) in meat products $(5 \mathrm{ng} / \mathrm{g})$. Ochratoxin $A$ is a primarily produced by species of Aspergillus and Penicillim and may cause damage of the kidneys and liver and is also considered as a suspected carcinogen. There is also going evidence that it impairs the immune system (Sizoo and Egmond, 2005).

Aflatoxin B1 contents (mean 15.3 and 9.8 $\mathrm{ng} / \mathrm{kg}$ ) were obtained from $4(20 \%)$ samples of meat luncheon and $3(15 \%)$ samples of chicken luncheon; respectively. Aflatoxin G1 and G2 were not detected in beef luncheon samples, while they were equally distributed in chicken luncheon samples (5\%), but at different concentrations $(10.2$ and $2.8 \mathrm{ng} / \mathrm{kg})$; respectively. Aflatoxin B2 was detected in (5\%) the beef and chicken luncheon samples, but at different concentrations (2.5 and $1.0 \mathrm{ng} / \mathrm{kg}$ ) respectively. Aflatoxins are considered as potent carcinogens and known to cause death in sheep and cattle. In addition, they may be involved in some human disease conditions (Atlas- Ronald, 1995).

Aflatoxins are group of the most potent mycotxins produced by Aspergillus flavus and related strains. They are their carcinogenic and found in frequency in nature. More specifically, AFB1, is one of the most potent aflatoxins. They are responsible for liver cancer in laboratory animals and even human-beings. They have been linked to a wide variety of human health problems. The FDA established maximum allowable levels of total aflatoxins in food commodities at 20 parts per billion (ppb) (Bullerman, 1979 and Bahgat, 1999).

\section{References}

A.O. A. C. (1984): Natural Poisons. Official Methods of Analysis of the Association of Official Analytical Chemists, pp., 447-484.

Ahmed, S. (1997): Incidence of mycotoxins and mycotoxin-producing moulds in some Egyptian dairy and meat products. $4^{\text {th }}$ Sci. Cong., Egyp. Soc. Cattle Dis. Assiut, pp., 74-80. 
Atlas-Ronald, M. (1995): Handbook of Microbiological Media for the Examination of Food. $2^{\text {nd }}$. (ed.), RC Press. Inc., Florida, USA.

Aziz, N. H. and Youssef, Y. A. (1991): Occurrence of aflatoxins and aflatoxin-producing moulds in fresh and processed meat in Egypt. Food Addit. Contam. , 8: 321-31. Bahgat, M. E. (1999): Mycotoxins. A potential universal everlasting threat: "Consumer's perspective" $5^{\text {th }}$ ed. Sci. Cong., Egyp. Soc. Cattle Dis. Assiut, pp., 22-35.

Bocarov-Stancic, A.; Protic, N. and Zivkovic, B. (1995): Review of microbiological investigations of feeds during 1992 and 1993 in the region Vojvodina. Biotechnologija Stocarstvu, 11: 63-68.

Bullerman, L. B. (1979): Significance of mycotoxins to food safety and human health. J. Food Prot., 42: 65-68.

Domsch, K. H.; Gams, W. and Anderson, T. (1993): Compendium of soil fungi. 1, ii, reprint IHW Verlag, Eching, Germany: 405- 859

Egmond, H. P.; Battaglia, R.; Hatzold, T. and Kroes, R. (1996): Analytical methodology and regulations for ochratoxin A.. Food Additives and Contaminants, 13: 1113.

Ellis, M. B. (1971): Dematiaceous Hyphomycetes . Commonw.Mycol. Inst. Kew , pp., 688 .

Farghaly, R. M. (1993): Occurrence and significance of toxic aspergilli in meat and meat products. Ph.D., Thesis, Fac. Vet. Med., Suez Canal Univ., Egypt.

FDA (1992): Food and Drug Administration "Aflatoxins and Aflatoxicosis" Food borne Pathogenic Microorganisms and Natural Toxins $2^{\text {nd }}$ ed. book, USA.

Fishbein, L. (1972): Natural non-nutrient substances in the food chain. The Science of The Total Environment. 1: 211244

George, A. and Lechtman, D. (1973): Microbiology and Human Disease, $2^{\text {nd }}$ ed. Glencoe Press, a Division of Benziger Bruce \&Glico, Inc. Beverly Hills. 403-405.

Gimeno, A. (1979): Thin layer chromatographic determinaiton of aflatoxins, ochratoxins, sterigmatocystin, zearalenone, citrinin, $\mathrm{T}-2$ toxin, diaceto-xyscirpenol and patulin. J. Assoc. Analy. Chem., 62: 579-585.

Giuseppe, C.; Sandi, O.; Sulejman, R.; Rosalinda, U. and Lucila, I. (2004): Moulds isolated from Istrian dried ham at the pre-ripening and ripening level, Int. J. Food Microbiol., 96 : 29- 34.
Hanlin, R. T. (1973): Keys to the families, genera and species of the Mucorales. J. Cramer Verlag, 3: 49.

Haschek, W. M. and Colin, G. R. (1991): Handbook of Toxicologic Pathology. Academic Press, New York.

Hess, J. B.; Bilgili, S. F.; Kelly, T. F.; Shelby, R. A. and Casper, H. (1995): Mould and mycotoxin levels in feeds from farms experiencing spiking mortality. J. Appl. Poult. Res., 4 (2): 211-214.

Ismail, M. A. and Zaky, Z. M. (1999): Evaluation of the mycological status of luncheon meat with special reference to aflatoxigenic moulds and aflatoxin residues. : Mycopathologia; 146 (3): 147-54.

Khan, M. F.; Hussain, A.; Ayaz, M.; Siddique, M. and Kausar, R. (1998): Chemical treatment of mouldy maize grain with aqueous ammonia and its feeding value to broiler chicks. Sarhad J. of Agri., 14 (6): 645 - 649.

Mahmoud, A. L .E.; Sayed, A. M. and Abou Abd ElAlla, A. A. (2001): Mycoflora and Natural Occurrence of Mycotoxins in Some Meat Products and Livers of Poultry and Imported Bulls. Pakistan J. Biological Sci., 4 (5): 611613.

Nesheim, S.; Hardin, N. F.; Francis, J. O. J. and Langham, W. S. (1973): Analysis of ochratoxins A and B and their esters in barley, using partition and thin layer chromatgraph, I-Development of the method. J. Assoc. Off. Anal. Chem., 56: 817-821.

Samson, R. A. and Hoekstra, E. S. (1996): Introduction To Food-Borne Fungi. Chap. 1: 172- 177 Centeraalbureae voor Schimmelcultures, The Netherlands.

Scott, P. M.; Walbeek, W. V.; Kennedy, B. P. C. and Anyeti, D. (1972): Mycotoxins (Ochratoxin A, Citrinin and Sterigmatocystin) and toxigenic fungi in grains and other agricultural products. J. Agr. Food Chem., 20: 1103-1109.

Sheng, W. and Jiu, Y. (2003): Ochratoxin A and human health. Med. Pub. Health J., 32: 172- 177.

Schroeder, H. W. and Kalton, W. H. (1975): Production of sterigmatosystin by some species of the genus Aspergillus and its toxicity to chicken embryos. Appl. Microbiol., 30: 583- 585.

Sizoo E. A. and Egmond H. P. (2005): Analysis of duplicate 24-hour diet samples for aflatoxin B1, aflatoxin M1 and ochratoxin A. Food Addit. Contam., 22: 163-172.

Zaki, Z. M.; Ismail, M. A. and Refaie, R. S. (1995): Aspergillus flavus and aflatoxins residues in luncheon meat. Assiut Vet. Med. J., 33: 114-117. 